\title{
Mitral valve replacement in mitral stenosis; the problem of small left ventricle
}

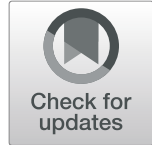

Hesham Alkady ${ }^{\text {* }}$, Ahmed Saber ${ }^{1}$, Sobhy Abouramadan ${ }^{1}$, Ahmed Elnaggar ${ }^{1}$, Sherif Nasr $^{2}$ and Eman Mahmoud ${ }^{3}$

\begin{abstract}
Background: Mitral valve stenosis in adults especially due to rheumatic heart disease may be associated with a smaller than normal left ventricular cavity. Mitral valve replacement in such cases may lead to hemodynamic instability either during weaning from cardiopulmonary bypass or in the early postoperative period manifested by the need for inotropic support and even mortality due to low cardiac output syndrome.

Patients and methods: 184 patients with predominately severe stenotic mitral valves who underwent elective isolated mitral valve replacement in the period between January 2012 and January 2018 at our hospital were included in this study. Patients were divided into 2 matched groups; (small LV group) consisting of 86 cases and (normal or dilated LV group) consisting of 98 cases.
\end{abstract}

Results: There were no statistically significant differences in operative details among both groups apart from the need for inotropic support and intra-aortic balloon pump due to low cardiac output which were statistically significantly higher in (small LV group) than (normal or dilated LV group) with a p-values of 0.01 and 0.03 respectively. Within the ICU stay only the incidence of occurrence of heart failure was significantly higher in (small LV group) with a $p$-value of 0.008 . No statistically significant difference could be elicited in the in-hospital mortality between both groups ( $p$-value $=0.1$ ).

Conclusion: Patients with mitral valve stenosis and small left ventricular cavity are in a higher need for inotropic and even mechanical support after mitral valve replacement as well as at a higher risk for the development of heart failure before hospital discharge than patients with mitral stenosis and normal-sized left ventricular cavity.

Keywords: Mitral stenosis, Mitral valve replacement, Small left ventricular cavity, Heart failure, Low cardiac output syndrome

\section{Background}

Mitral valve stenosis (MS) in adults especially due to rheumatic heart disease may be associated with a smaller than normal left ventricular cavity. This might be attributed to inadequate left ventricular preloading or chronic myocardial damage due to rheumatic heart disease resulting in left ventricular atrophy [1]. Sudden increase of blood inflow from the left atrium to the small "unprepared" left ventricle after mitral valve replacement

* Correspondence: heshamalqady@cu.edu.eg

${ }^{1}$ Department of cardiothoracic surgery, Cairo University, Kasralaini str., Almanial, Cairo, Egypt

Full list of author information is available at the end of the article
(MVR) in such cases may lead to hemodynamic instability either during weaning from cardiopulmonary bypass $(\mathrm{CPB})$ or in the early postoperative period manifested by the need for inotropic support and even mortality due to low cardiac output (COP) syndrome [2]. In this study we share our experience with the outcomes of mitral valve replacement in patients with long-standing severe mitral stenosis and small left ventricular cavity.

\section{Patients and methods}

In this study the data of 86 consecutive patients with predominately severe stenotic mitral valves (mitral regurgitation $\leq+2$ ) and small left ventricular cavity 
(determined by the lower reference values from the NORRE study according to age, gender and body surface area) [3] who underwent elective isolated MVR in the period between January 2012 and January 2018 at our hospital were retrospectively collected and analyzed (small LV group). Another group of 98 patients with predominately severe stenotic mitral valves but with normal-sized or dilated left ventricles who underwent elective isolated MVR over the same period were matched to (small LV group) using propensity scores according to preoperative patient characteristics (normal or dilated LV group). All these cases were not amenable to balloon mitral valvoplasty either due to excessive calcification at the leaflet tips or the presence of left atrial thrombus. Cases associated with any other significant valvular or coronary artery diseases necessitating surgical intervention were not included. In addition, patients with impaired left ventricular function (ejection fraction $\leq 50$ ) were excluded. Our study was approved by the institutional ethical board and because of its retrospective nature, patient consent was waived. All patients received preoperative transthoracic 2D-echocardiography to evaluate the mitral as well as other cardiac valves and all cardiac chambers. Coronary angiography was done for patients aged $>45$ years preoperatively to delineate any coronary artery disease. Severe MS necessitating surgery was defined by a mitral valve area (MVA) of < $1.0 \mathrm{~cm}^{2}$ and a mean pressure gradient across the mitral valve of $>10 \mathrm{mmHg}$. Grading of associated mitral regurgitation (MR) was carried on according to jet area and Vena contracta [4]. The size of the left ventricular cavity was assessed through echocardiography using the Simpson's biplane method [5]. Preoperative, operative and postoperative data were obtained from hospital records and were compared for both groups regarding; the size and type of implanted prosthesis, intra-operative time parameters (aortic cross-clamp, $\mathrm{CPB}$ and total operative times), need for inotropic support (Epinephrine infusion) or intra-aortic balloon counter-pulsation (IABP) during weaning from CPB to maintain mean arterial blood pressure $>90 \mathrm{mHg}$, duration of mechanical ventilation and ICU stay, occurrence of postoperative complications (heart failure, renal impairment, cerebro-vascular stroke and bleeding), in-hospital mortality and total hospital stay. Heart failure was defined as dyspnea or impaired arterial blood gases in association with radiographic signs of pulmonary congestion. Renal impairment was defined as an increase in the serum creatinine to $>2$ $\mathrm{mg} / \mathrm{dl}$ or twice the level of preoperative creatinine. Patients were followed up through outpatient clinics and telephone calls regarding late occurrence of heart failure and cardiac mortality.

\section{Statistical analysis}

Data were coded and then entered into the SPSS statistical package (Statistical Package for the Social Sciences) version 22. Quantitative data were summarized using the mean \pm standard deviation, while categorical data were presented as frequency (count) and relative frequency (percentage). The means of continuous variables were compared between groups by Student's t-test while rates and proportions were compared by the Chi Square or Fisher exact tests. The propensity score matching was obtained by multiple logistic regression, based on preoperative patient characteristics (Table 1). A $p$-value < 0.05 was considered as significant. Kaplan-Meier curves were used to determine survival and freedom from heart failure.

\section{Results}

\section{Preoperative characteristics}

All patients were in New York Heart Association (NYHA) class III preoperatively. Table 1 summarizes preoperative epidemiological, clinical and echocardiographical data. There were no statistically significant differences between both groups regarding preoperative patient characteristics apart from left ventricular enddiastolic and end-systolic diameters as well as enddiastolic volume index. In addition, (normal or dilated LV group) had significantly higher degrees of associated mitral regurgitation (MR) than (small LV group) with a $p$-value of 0.01 .

\section{Operative data}

In (small LV group) 36 patients (42\%) were operated upon minimally invasive through right anterolateral minithoracotomy in the 5th intercostal space, 15 patients (17\%) through lower ministernotomy till the 4th intercostal space and the rest (35 patients) were operated upon conventionally through full median sternotomy. On the other hand, in (normal or dilated LV group) 44 patients (45\%) were operated upon through right anterolateral minithoracotomy, 18 patients (18\%) through lower ministernotomy and the rest (36 patients) were operated upon through full median sternotomy. These different techniques are attributed to our program in minimally invasive mitral valve surgery which was established later in the study in 2014 and was started with the ministernotomy incision and then shifted to the right minithoracotomy incision in 2015. The pathology of mitral valve stenosis was rheumatic in origin in both groups except for 2 cases (2\%) in (small LV group) and 3 patients (3\%) in (normal or dilated LV group), where stenosis was attributed to degenerative changes. Significant mitral annular calcification (MAC) was not encountered in our study patients [6]. The mitral valve was replaced through left atriotomy in full sternotomy as 
Table 1 Preoperative patient characteristics. AF; atrial fibrillation, CVS; cerebrovascular stroke, COPD; chronic obstructive pulmonary disease, CRF; chronic renal failure, LVEDD; left ventricular end-diastolic diameter, LVESD; left ventricular end-systolic diameter, LVEDV; left ventricular end-diastolic volume, PG; pressure gradient

\begin{tabular}{|c|c|c|c|}
\hline Preoperative patient characteristics & Small LV group $(N=86)$ & Normal or dilated LV group $(N=98)$ & $P$-value \\
\hline Age (years) & $34 \pm 7$ & $35 \pm 8$ & 0.02 \\
\hline \multicolumn{4}{|l|}{ Gender } \\
\hline Males/Females & $36(42 \%) / 50(58 \%)$ & $46(47 \%) / 52(53 \%)$ & 0.49 \\
\hline Body surface area $\left(\mathrm{m}^{2}\right)$ & $1.68 \pm 0.12$ & $1.71 \pm 0.16$ & 0.15 \\
\hline Chronic AF & $58(67 \%)$ & $68(69 \%)$ & 0.78 \\
\hline Previous CVS & $18(21 \%)$ & $25(25.5 \%)$ & 0.46 \\
\hline Previous balloon commisurotomy & $24(28 \%)$ & $37(38 \%)$ & 0.16 \\
\hline \multicolumn{4}{|l|}{ Co-morbidities } \\
\hline Diabetes mellitus & $6(7 \%)$ & $8(8 \%)$ & 0.76 \\
\hline Systemic hypertension & $5(5.8 \%)$ & $3(3 \%)$ & 0.36 \\
\hline COPD & $2(2 \%)$ & $2(2 \%)$ & 0.89 \\
\hline Residual hemiparesis after previous CVS & $4(4.6 \%)$ & $6(6.1 \%)$ & 0.66 \\
\hline CRF on regular dialysis & $1(1.16 \%)$ & - & 0.46 \\
\hline \multicolumn{4}{|l|}{ Preoperative Echocardiographic date } \\
\hline Mean LVEDD (cm) & $4.94 \pm 0.80$ & $5.51 \pm 1.70$ & 0.002 \\
\hline Mean LVESD (cm) & $3.35 \pm 0.18$ & $3.54 \pm 0.30$ & 0.001 \\
\hline Mean LVEDV index $\left(\mathrm{ml} / \mathrm{m}^{2}\right)$ & $34.48 \pm 2.7$ & $65.67 \pm 3.4$ & 0.001 \\
\hline Mean mitral valve area $\left(\mathrm{cm}^{2}\right)$ & $0.61 \pm 0.20$ & $0.62 \pm 0.60$ & 0.14 \\
\hline Mean PG across the mitral valve $(\mathrm{mmHg})$ & $20.68 \pm 2.56$ & $20.03 \pm 2.36$ & 0.08 \\
\hline Degree of associated mitral regurgitation & & & 0.001 \\
\hline$\leq+1$ & $75(87 \%)$ & $8(8 \%)$ & \\
\hline$\leq+2$ & $11(13 \%)$ & $90(92 \%)$ & \\
\hline Mean left atrial diameter (cm) & $5.12 \pm 0.58$ & $5.28 \pm 0.61$ & 0.07 \\
\hline Mean pulmonary artery pressure (mmHg) & $54.17 \pm 9.08$ & $51.78 \pm 9.60$ & 0.08 \\
\hline Evidence of left atrial thrombus & 5 & 7 & 0.72 \\
\hline
\end{tabular}

well as right minithoracotomy cases and was replaced through the transseptal approach in lower ministernotomy cases. Myocardial protection was done in all patients through ante-grade cold blood cardioplegia via the aortic root as well as moderate hypothermia (rectal temperature, $28^{\circ} \mathrm{C}$ ). In all cases preservation of the posterior mitral leaflet could be done. All patients received St. Jude mechanical mitral prostheses (SJM; St. Jude Medical Inc.; Minneapolis, Minn). Table 2 shows the different techniques used for MVR, the sizes of used mechanical prostheses, intra-operative time parameters as well as need for inotropic support and IABP in both groups. There were no statistically significant differences in operative details among both groups apart from the need for inotropic support and IABP due to early low COP (immediately after weaning from CBP) which was statistically significantly higher in (small LV group) than (normal or dilated LV group) with a $p$-values of 0.01 and 0.03 respectively.

\section{Postoperative results}

Table 3 shows the postoperative outcomes. There were no statistically significant differences between both groups in concern of postoperative complications apart from the occurrence of heart failure within the ICU stay ( $p$-value $=0.008)$ which was significantly higher in (small LV group). These cases were managed by increasing the doses of inotropes as well as vigorous diuresis. There were 3 in-hospital mortalities in (small LV group) due to refractory low COP syndrome despite maximal inotropic support and IABP. On the other hand no in-hospital mortality occurred in (normal or dilated LV group). However despite this difference in the in-hospital mortality between both groups, no statistical significance could be elicited ( $p$-value $=0.10)$.

96.5\% of patients in (small LV group) and $94.9 \%$ of patients in (normal or dilated LV group) could be followed up for a mean period of $2 \pm 1.2$ years after discharge. There was no statistically significant difference between 
Table 2 Operative data. MS; mitral stenosis, MVR; mitral valve replacement, CPB; cardiopulmonary bypass, IABP; intra-aortic balloon pump, COP; cardiac output

\begin{tabular}{|c|c|c|c|}
\hline Operative data & Small LV group $(N=86)$ & Normal or dilated LV group $(N=98)$ & $P$-value \\
\hline Pathology of MS & & & 0.76 \\
\hline Rheumatic & $84(98 \%)$ & $95(97 \%)$ & \\
\hline Degenerative & $2(2 \%)$ & $3(3 \%)$ & \\
\hline Techniques of MVR & & & 0.50 \\
\hline Full median sternotomy & $35(41 \%)$ & $36(37 \%)$ & \\
\hline Lower ministernotomy & $15(17 \%)$ & $18(18 \%)$ & \\
\hline Right anterolateral minithoracotomy & $36(42 \%)$ & $44(45 \%)$ & \\
\hline Sizes of mitral prostheses $(\mathrm{mm})$ & & & 0.50 \\
\hline 25 & 2 & 1 & \\
\hline 27 & 80 & 89 & \\
\hline 29 & 4 & 8 & \\
\hline \multicolumn{4}{|l|}{ Intra-operative time parameters (min) } \\
\hline Total operative time & $219.25 \pm 19.86$ & $213.70 \pm 22.12$ & 0.07 \\
\hline CPB time & $85.67 \pm 7.72$ & $83.43 \pm 8.06$ & 0.06 \\
\hline Cross-clamp time & $67.80 \pm 10.23$ & $69.37 \pm 9.21$ & 0.27 \\
\hline Need for inotropic support & $80(93 \%)$ & $60(45 \%)$ & 0.01 \\
\hline Need for IABP due to low COP syndrome & $6(7 \%)$ & $1(1 \%)$ & 0.03 \\
\hline
\end{tabular}

both groups during the follow up period in mortality; one in (small LV group) due to endocarditis after 8 months and one in (normal or dilated LV group) after 16 months due to massive valve thrombosis or in readmission due to heart failure; two patients in both groups after 3 and 4 months respectively. Figs 1 and 2

\section{Discussion}

There is little information in the literature regarding the physiologic and structural effects of mitral stenosis, especially of rheumatic origin, on the left ventricle and its size $[7,8]$. However, in our practice, the association of predominately severe mitral stenosis and small left ventricular cavity is not uncommon especially when the degree of associated mitral regurgitation is minimal. This was obvious in our study cohort where patients in (normal or dilated LV group) had significantly higher degrees of associated mitral regurgitation. The increase in the size of the left ventricular cavity in this group may be attributed to the higher preload conditioning of the left ventricle from associated mitral regurgitation. Also the pathology of mitral stenosis in our community is still mainly due to rheumatic heart disease rather than degenerative processes.

Repair of stenotic mitral valves especially due to rheumatic pathology, although remains better than replacement,

Table 3 Postoperative results

\begin{tabular}{llll}
\hline Postoperative results & Small LV group (N=86) & Normal or dilated LV group (N=98) & $P$-value \\
\hline Duration of mechanical ventilation (hours) & $6.46 \pm 1.38$ & $6.08 \pm 1.36$ & 0.06 \\
Duration of ICU stay (days) & $3.76 \pm 1.05$ & $3.48 \pm 1.08$ & 0.07 \\
Total hospital stay (days) & $8.87 \pm 1.18$ & $8.59 \pm 0.90$ & 0.07 \\
Postoperative complications & & & 0.75 \\
$\quad$ Renal failure & $2(2.5 \%)$ & $3(3 \%)$ & 0.53 \\
$\quad-\quad$ & $1(1 \%)$ & $\mathbf{0 . 0 0 8}$ \\
$\quad$ Heart failure & $1(11.6 \%)$ & - & 0.47 \\
$\quad$ Re-exploration for bleeding & $1(1.16 \%)$ & - & 0.10 \\
\hline In-hospital mortality & $3(3.4 \%)$ & & \\
\hline
\end{tabular}




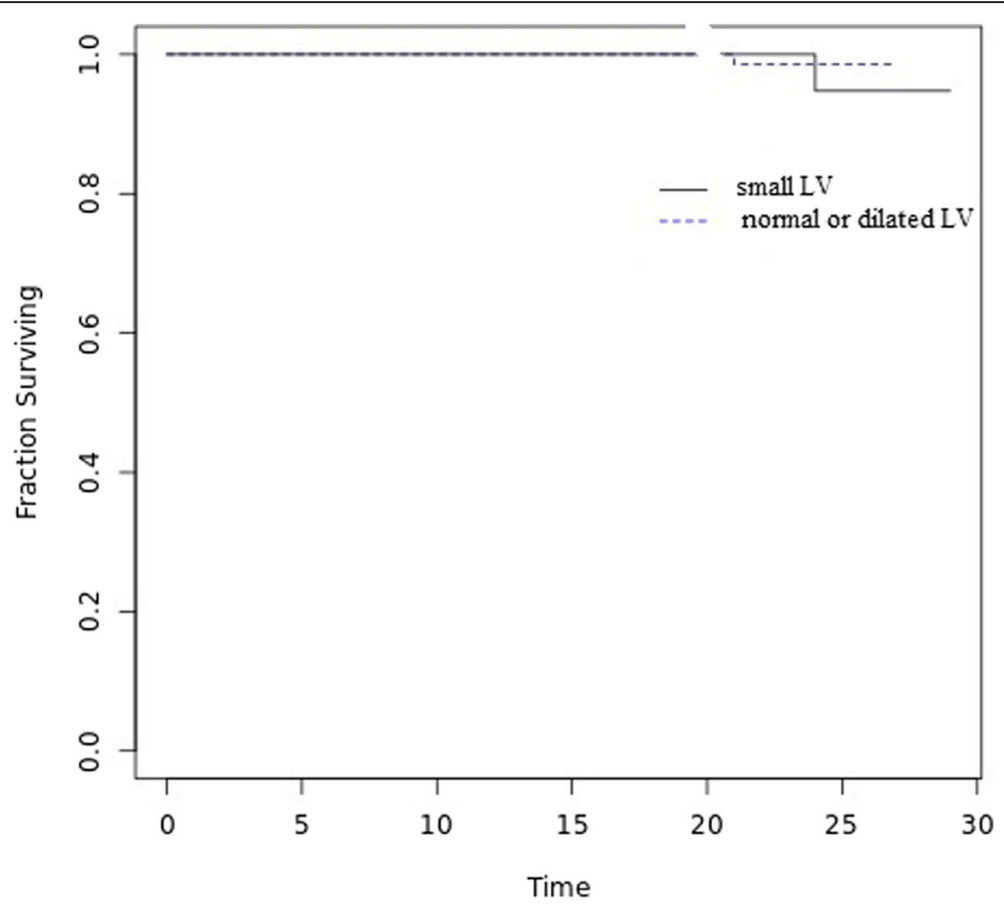

Fig. 1 Kaplan-Meier curve showing survival in both groups during the follow-up period

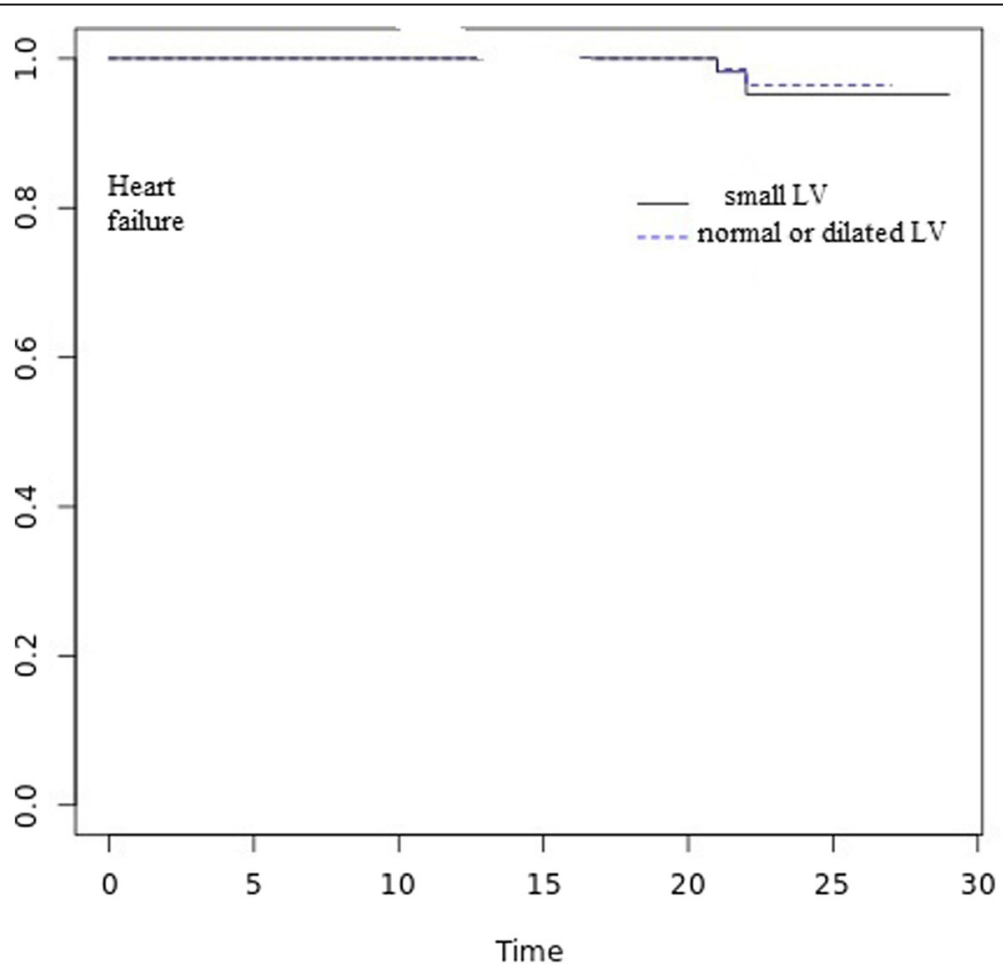

Fig. 2 Kaplan-Meier curve showing the occurrence of heart failure in both groups during the follow-up period 
is not easy in many cases and the surgeon may be forced to replace the valve if repair is considered impossible or non-durable $[9,10]$. Mitral valve replacement in chronic mitral valve stenosis with small left ventricular cavity especially due to rheumatic cause may be associated with systolic left ventricular dysfunction after weaning from cardiopulmonary bypass and/ or early postoperative period. This is in part due to the sudden volume overload of the small left ventricle not accustomed to the increased blood influx from the left atrium as well as due to partial or even complete excision of one or both mitral leaflets and subvalvular apparatus during mitral valve replacement [11]. Although no doubt exists regarding importance of the mitral valve apparatus including the chordea tendinea and papillary muscles to left ventricular contractility and every effort is to be made to preserve as much as possible of the mitral valve during replacement $[12,13]$. However this might be difficult in mitral stenosis due to the need for placing a prosthesis with an adequate size to avoid patient prosthesis mismatch (PPM) which is defined as placing a small prosthesis in relation to the body surface area with an effective orifice area (EOA) index $\leq 1.2 \mathrm{~cm} 2 / \mathrm{m} 2$ $[14,15]$. Such PPM is proved to be associated with a residual pressure gradient across the mitral valve resulting in the persistence of pulmonary hypertension and recurrence or increase of associated functional tricuspid regurgitation $[16,17]$. Therefore we routinely preserve the posterior mitral leaflet during mitral valve replacement in mitral stenosis to ameliorate the postoperative left ventricular systolic dysfunction. In addition we do not support at all the idea of placing a small-sized prosthetic valve like $25 \mathrm{~mm}$ in such patients as an attempt to avoid the early left ventricular systolic dysfunction after MVR [2]. We always try to place the largest possible prosthetic valve for fear of PPM on the long run.

According to our study patients with MS and small left ventricle needed more inotropic support and IABP during weaning off CBP after MVR to maintain a mean arterial blood pressure $>90 \mathrm{mmHg}(P$ value $=0.01$ and 0.03 respectively) and showed higher incidence of heart failure before discharge from ICU ( $p$-value $=0.008)$. This is why in such patients we tend to use a reasonable dose of inotropes (e.g. Epinephrine at a rate of $50 \mathrm{ng} / \mathrm{kg}$ per minute as a continuous infusion) almost routinely during weaning off CBP and withdraw this inotropic support very gradually on the first postoperative day. In addition intravenous volume intake should be carefully administered both during weaning off CBP and during the ICU stay.

Finally our study has some limitations in the form of the retrospective nature and single-center experience. In addition, no significantly higher mortality could be elicited both during the primary hospital stay or the follow up period in patients with mitral stenosis and small left ventricle undergoing MVR. Therefore more future studies with larger cohort may be needed.

\section{Conclusion}

Patients with mitral valve stenosis and small left ventricular cavity are in a higher need for inotropic and even mechanical support after mitral valve replacement as well as at a higher risk for the development of heart failure before hospital discharge than patients with mitral stenosis and normal-sized left ventricular cavity. Therefore inotropic support should be used expediently after weaning from cardiopulmonary bypass and withdrawn carefully during early postoperative period after MVR in such patients.

\section{Abbreviations}

COP: Cardiac output syndrome; CPB: Cardiopulmonary bypass; EOA: Effective orifice area; IABP: Intra-aortic balloon counter-pulsation; LV: Left ventricle; MAC: Mitral annular calcification; MR: Mitral regurgitation; MS: Mitral stenosis; MVA: Mitral valve area; MVR: Mitral valve replacement; NYHA: New York Heart Association; PPM: Patient prosthesis mismatch

\section{Acknowledgements}

Not applicable.

Authors' contributions

All authors participated in data collection and analysis. All authors read and approved the final manuscript.

Funding

Not applicable.

Availability of data and materials

The datasets used and/or analysed during the current study are available from the corresponding author on reasonable request.

Ethics approval and consent to participate

This study was approved by the institutional ethical board.

Consent for publication

Because of the retrospective nature of the study, patient consent was waived.

Competing interests

The authors declare that they have no competing interests.

\section{Author details}

${ }^{1}$ Department of cardiothoracic surgery, Cairo University, Kasralaini str., Almanial, Cairo, Egypt. ²Department of cardiothoracic surgery, Fayoum University, Fayoum, Egypt. ${ }^{3}$ Department of cardiology, Fayoum University, Fayoum, Egypt.

Received: 4 December 2019 Accepted: 13 April 2020

Published online: 22 April 2020

\section{References}

1. Popov V, Lazoryshinets V, Shimon V, Lukach Y. Mitral valve replacement with small cavity of left ventricle. J Cardiothorac Surg. 2013:8:288.

2. Zhang ZW, Gu TX. Prosthesis size selection for patients with severe mitral stenosis. Ann Thorac Surg. 2017;103:1359-62.

3. Kou S, Caballero L, Dulgheru R, Voilliot D, De Sousa C, Kacharava G, Athanassopoulos GD, Barone D, Baroni M, Cardim N, Gomez De Diego JJ, Hagendorff A, Henri C, Hristova K, Lopez T, Magne J, De La Morena G Popescu BA, Penicka M, Ozyigit T, Rodrigo Carbonero JD, Salustri A, Van De Veire N, Von Bardeleben RS, Vinereanu D, Voigt JU, Zamorano IL, Donal E, Lang RM, Badano LP, Lancellotti P. Echocardiographic reference ranges for 
normal cardiac chamber size: results from the NORRE study. Eur Heart J Cardiovasc Imaging. 2014;15:680-90.

4. Baumgartner H, Falk V, Bax JJ, De Bonis M, Hamm C, Holm PJ, lung B, Lancellotti P, Lansac E, Rodriguez Muñoz D, Rosenhek R, Sjögren J, Tornos Mas P, Vahanian A, Walther T, Wendler O, Windecker S, Zamorano JL. ESC scientific document group. 2017 ESC/EACTS guidelines for the management of valvular heart disease. Eur Heart J. 2017;38:2739-91.

5. Gibson PH, Becher H, Choy JB. Classification of left ventricular size: diameter or volume with contrast echocardiography? Open Heart. 2014;1:000147.

6. Ramaraj R, Manrique C, Hashemzadeh M, Movahed MR. Mitral annulus calcification is independently associated with all-cause mortality. Exp Clin Cardiol. 2013;18:5-7.

7. Meyer M. Left ventricular atrophy in pulmonary arterial hypertension: a sinister Dexter conundrum. J Am Coll Cardiol. 2014;64:38-40.

8. Baumgartner $\mathrm{H}$, Hung J, Bermejo J, Chambers JB, Evangelista A, Griffin BP, lung B, Otto CM, Pellikka PA. Qui ones M; American Society of Echocardiography; European Association of Echocardiography: echocardiographic assessment of valve stenosis: EAE/ASE recommendations for clinical practice. J Am Soc Echocardiogr. 2009;22:1-23.

9. Rajbanshi BG, Suri RM, Nkomo VT, Dearani JA, Daly RC, Burkhart HM, Stulak $J M$, Joyce LD, Li Z, Schaff HV. Influence of mitral valve repair versus replacement on the development of late functional tricuspid regurgitation. J Thorac Cardiovasc Surg. 2014;148:1957-62.

10. Kim JB, Kim HJ, Moon DH, Jung SH, Choo SJ, Chung CH, Song H, Lee JW. Long-term outcomes after surgery for rheumatic mitral valve disease: valve repair versus mechanical valve replacement. Eur J Cardiothorac Surg. 2010; 37:1039-46.

11. Essandoh MK. Echocardiographic features that may predict acute left ventricular failure after mitral valve replacement in patients with severe mitral stenosis. Anesthesiology. 2016;125:808.

12. Merwe J, Casselman F. Mitral valve replacement-current and future perspectives. Open Journal of Cardiovascular Surgery. 2017;9:1-6.

13. Ahmed CM, Husain SSH, Zaman SMM, Osmany DMMF, Fatema N, Salim F, Arzu J. Mechanism for differences in postoperative left ventricular ejection fraction after mitral valve replacement in patients with mitral stenosis. Ann Int Med Den Res. 2018;4:44-7.

14. Shi WY, Yap CH, Hayward PA, Dinh DT, Reid CM, Shardey GC, Smith JA. Impact of prosthesispatient mismatch after mitral valve replacement: a multicenter analysis of early outcomes and mid-term survival. Heart. 2011; 97:1074-81.

15. Lee $\mathrm{SH}$, Chang BC, Youn YN, Joo HC, Yoo KJ, Lee S. Impact of prosthesispatient mismatch after mitral valve replacement in rheumatic population: does mitral position prosthesis-patient mismatch really exist? J Cardiothorac Surg. 2017;12:88.

16. Hwang HY, Kim YH, Kim KH, Kim KB, Ahn H. Patient-prosthesis mismatch after mitral valve replacement: a propensity score analysis. Ann Thorac Surg. 2016;101:1796-803.

17. Angeloni E, Melina G, Benedetto U, Roscitano A, Refice S, Quarto C, Comito C, Pibarot P, Sinatra R. Impact of prosthesis-patient mismatch on tricuspid valve regurgitation and pulmonary hypertension following mitral valve replacement. Int J Cardiol. 2013;168:4150-4.

\section{Publisher's Note}

Springer Nature remains neutral with regard to jurisdictional claims in published maps and institutional affiliations.

Ready to submit your research? Choose BMC and benefit from:

- fast, convenient online submission

- thorough peer review by experienced researchers in your field

- rapid publication on acceptance

- support for research data, including large and complex data types

- gold Open Access which fosters wider collaboration and increased citations

- maximum visibility for your research: over $100 \mathrm{M}$ website views per year

At BMC, research is always in progress.

Learn more biomedcentral.com/submissions 